\title{
Distribution of Biomarkers and Its Record for Paleoclimate in Linxia Basin, NE Tibetan Plateau, NW China
}

YONGLi WANG ${ }^{1}, \mathrm{HE} \mathrm{MA}^{1,2}$, JiNGYI WEI $^{1,2}$, SHENGGUANG ZHUO $^{3}$, ZHIFU WEI ${ }^{4}$, GEN WANG ${ }^{4}$, YINGQIN WU ${ }^{4}$, YAN $\mathrm{LIU}^{4}$, HUI YANG ${ }^{4}$, YouXIAO WANG ${ }^{4}$

${ }^{1}$ Institute of Geology and Geophysics, Chinese Academy of Sciences, Beijing 100029, China

${ }^{2}$ University of Chinese Academy of Sciences, Beijing 100049, China

${ }^{3}$ Northeastern University at Qinhuangdao, Qinhuangdao 066004, China

${ }^{4}$ Northwest Institute of Eco-Environment and Resources, Chinese Academy of Sciences, Lanzhou 730000, China

The use of fossil molecules to reconstruct paleoclimate has become an important part of molecular stratigraphy. Fossil Molecules have the characteristics of stable compounds, long-time preservation and wide distribution, providing great information on climatic and environmental changes, provenience of parent materials, redox degree of organic matters, development status of bacteria and microorganisms in ancient environments, different ecology and vegetation systems, past water salinity, and thermal evolution degree of organic matter. Many types of biomarkers have been reported, such as alkanes, aromatics, alkanoic acids, alkanols, alkenones and esters. The most researches are mainly focused on the category, concentration, relative abundance of biomarker compounds, and the compositions of stable isotopes such as monomer carbon, hydrogen, oxygen and nitrogen. The research targets have reached aerosol, marine sediments, lacustrine and peat sediments, glacier, ancient vegetation, loess, cave stalagmite, and estuarine sediments (rocks).

$\mathrm{n}$-Alkanes and $\delta^{13} \mathrm{C}$ values of TOC were detected in 229 samples in the lacustrine sediments of Maogou section in the Linxia Basin ( Fig.1.), NE Tibetan Plateau, NW China. Their distribution characteristics are corresponding to arid climate change in the inland Asia from 29Ma to 4.3Ma. Our observation from biomarker climate indicators agrees with previous literature reports with the study of Palynofloras on the climate change in the investigated region commonly responds to the uplift of the Tibetan Plateau at $\sim 8 \mathrm{Ma}$.

This study shows that biomarkers could be an important climate indicators to the arid environmental change in the inland Asia. The use of biomarkers to reconstruct paleoclimate has attracted increasing interest and has become an important part of molecular stratigraphy. 